\title{
Interactions between PRP9 and SPP91 splicing factors identify a protein complex required in prespliceosome assembly
}

\author{
Pierre Legrain, ${ }^{1}$ Christine Chapon, and Frédérique Galisson \\ Unité de Génétique Moléculaire des Levures, Département de Biologie Moléculaire, Institut Pasteur, \\ Paris 75724, Cedex 15, France
}

\begin{abstract}
The PRP9 protein is a yeast splicing factor implicated in the early steps of spliceosome assembly whose sequence contains an amino-terminal putative leucine zipper structure and two carboxy-terminal motifs reminiscent of zinc fingers. Here, we show that the deletion of the second carboxy-terminal motif results in a dominant lethal phenotype. This observation, combined with an in vivo-binding assay for protein-protein interactions, reveals the presence of two distinct binding sites on the PRP9 protein. The carboxy-terminal region contributes to the PRP9 homodimerization, whereas the amino-terminal region binds the SPP91 splicing factor. Further experiments suggest that other factors bind to PRP9 and SPP91 proteins. Finally, we demonstrate that the PRP9 protein acts after the formation of the U1 snRNP-pre-mRNA complex. The existence of a protein complex including the PRP9 factor is discussed.
\end{abstract}

[Key Words: PRP; yeast; GAL4 fusion protein; pre-mRNA splicing]

Received March 15, 1993; revised version accepted April 28, 1993.

Nuclear introns are excised from pre-mRNA precursors via two trans-esterification reactions taking place in a multimolecular complex called the spliceosome (for review, see Green 1991; Guthrie 1991; Rymond and Rosbash 1992; Moore et al. 1993). This mechanism has been analyzed primarily in vitro and is conserved between the yeast Saccharomyces cerevisiae and higher eukaryotes. The spliceosome forms on the newly transcribed premRNA by the ordered addition of soluble proteins and the four ribonucleoprotein particles, containing, respectively the U1, U2, U4 and U6 (U4/U6), and U5 snRNAs (Frendewey and Keller 1985; Konarska and Sharp 1986; Pikielny et al. 1986; Cheng and Abelson 1987; Legrain et al. 1988; Seraphin and Rosbash 1989; Barabino et al. 1990; Kramer and Utans 1991; Michaud and Reed 1991). The initial Ul small nuclear ribonucleoprotein (snRNP) interaction with the pre-mRNA results in the formation of a commitment complex, the U2 snRNP then binds to this complex and, ultimately, the spliceosome assembles by the addition of the U4/U6 and U5 snRNPs as a preformed tri-snRNP.

Although multiple splicing factors have been identified, very little is known about the protein-protein interactions that occur during spliceosome assembly. Most of the identified interactions involve RNA-RNA base-

${ }^{1}$ Corresponding author. pairing between snRNAs, between pre-mRNA sequences, or between snRNA and the pre-mRNA (for review, see Moore et al. 1993), or interactions between proteins and RNAs (Bordonne et al. 1990; Scherly et al. 1990; Whittaker and Beggs 1991; Frank et al. 1992; Liao et al. 1993). In higher eukaryotes, several factors, such as U2AF, ASF/SF2, SF1, SF3, and SC35 proteins, have been shown to be required during the early steps of spliceosome assembly in association with U1 and U2 snRNPs (Ge et al. 1991; Krainer et al. 1991; Kramer and Utans 1991; Fu and Maniatis 1992b; Zamore et al. 1992), but relationships between these various factors remain unknown.

In $S$. cerevisiae, genetic studies have identified at least $30 P R P$ genes, including the $P R P 9$ gene, involved at various steps during spliceosome assembly or splicing reactions (Hartwell et al. 1970; Vijayraghavan et al. 1989). The functions of the PRP proteins have been identified primarily by the use of heat-sensitive prp alleles, for which in vitro and in vivo splicing defects have been characterized. In addition to a splicing defect, we observed that the prp9-1 mutant exhibits an increased premRNA nuclear export into the cytoplasm (Legrain and Rosbash 1989), suggesting that the PRP9 protein may act during the early steps of the spliceosome assembly pathway. In addition, the PRP9 protein is required in vitro for the formation of the pre-spliceosome, which contains the $\mathrm{U} 1$ and the $\mathrm{U} 2$ snRNPs, but is not tightly associated 
with the U2 snRNP (Abovich et al. 1990). A mammalian PRP9 homolog has been identified that is associated with the 17S U2 snRNP (Behrens et al. 1993b) and is also required for pre-spliceosome formation (Behrens et al. 1993a). Therefore, the binding of the PRP9 protein to the early splicing complexes could be an essential step for the in vivo commitment in the splicing pathway.

The PRP9 gene product contains two cysteine/histidine motifs ( $\mathrm{CH}$ motifs) loosely related to zinc finger motifs of the TFIIIA type and a putative leucine zipper domain (Legrain and Choulika 1990). Such motifs can be involved in protein-protein interactions. Recently, we isolated an extragenic suppressor, spp $91-1$, of the heatsensitive prp9-1 mutation. The combination of the prp9-1 mutation and a decreased expression of the SPP91 gene results in a synthetic lethal phenotype. These observations suggested possible interactions between PRP9 and SPP91 proteins (Chapon and Legrain 1992).

In this paper we show that the prp9 mutant deleted for the second $\mathrm{CH}$ motif exhibits a dominant lethal phenotype that leads us to postulate several binding properties for the PRP9 protein. By using an in vivo binding assay (Fields and Song 1989; Chien et al. 1991), we have identified and characterized a direct interaction between the PRP9 and SPP91 proteins and, in addition, have demonstrated that the PRP9 protein homodimerizes. These studies strongly suggest that the PRP9 and SPP91 proteins form a multimolecular complex, probably in association with additional factors. Finally, we show that the U1 snRNP-pre-mRNA complex forms in the absence of the PRP9 protein. Taken together, the properties of the PRP9 and SPP91 proteins suggest that the PRP9/SPP91 complex acts in the formation of the U1 snRNP/U2 snRNP/pre-mRNA prespliceosome complex.

\section{Results}

Deletion of the CH2 region of the PRP9 protein confers a dominant lethal phenotype in a prp9-1 genetic background

The PRP9 protein contains two motifs, referred to as $\mathrm{CH} 1$ and $\mathrm{CH} 2$ (Fig. 1), reminiscent of $\mathrm{Cys}_{2} \mathrm{His}_{2}$ zinc fingers. The function of these motifs was addressed previously by a complementation assay of the prp9-1 heatsensitive mutation with genes mutated in the cysteine and histidine codons (Legrain and Choulika 1990). The PRP9 proteins mutated in either the cysteine or histidine residues of the $\mathrm{CH} 2$ motif do not complement the prp9-1 mutation. By use of a plasmid-shuffling strategy, these
$\mathrm{CH} 2$ mutants were shown to be null alleles of the $P R P 9$ gene (data not shown). To investigate further the function of the $\mathrm{CH}$ domains, deletions covering each of these motifs were made (referred to as prp9 $9 \mathrm{CH} 1$ and prp94CH2). Surprisingly, when prp9-1 cells were transformed with a high-copy-number plasmid carrying the prp $9 \triangle \mathrm{CH} 2$ allele, very few transformants were obtained, although transformation efficiency with the prp $9 \Delta C H 1$ plasmid or the vector alone was normal (Table 1). This low efficiency of transformation was dose dependent, because the number of transformants increased slightly when a low-copy-number plasmid was used. We verified that expression of the prp $9 \triangle \mathrm{CH} 2$ allele was lethal by use of a GAL-prp $9 \triangle C H 2$ construct in which expression of the prp $94 \mathrm{CH} 2$ allele is directed from a galactose-inducible promoter. With this construct, prp9-1 cells are viable when plated on glucose-containing medium, and lethality is observed after transfer of the cells to galactose-containing medium (Fig. 2). This dominant lethal phenotype was observed only in prp9-1 or prp9-2 cells (Vijayraghavan et al. 1989) and not in wild-type cells or in prp 9-1 cells cotransformed with a wild-type $P R P 9$ allele (data not shown). In addition, the double mutant carrying the tsl mutation and the $\mathrm{CH} 2$ deletion did not affect the transformation efficiency of prp9-1 cells $(\mathrm{Ta}-$ ble 1).

The growth rates of prp9-1 cells transformed with the GAL-prp9 9 CH2 plasmid or the control vector, pLGSD5, were monitored in glucose- or galactose-containing media (Fig. 3, top). In the presence of glucose or galactose, prp9-1 cells transformed with the pLGSD5 vector have very similar growth rates (left panel). In contrast, $12 \mathrm{hr}$ after transfer to galactose-containing medium (i.e., two doubling times), the growth rate of GAL-prp9ACH2transformed cells decreases (right panel). The splicing efficiencies in these transformed prp9-1 cells were me $\hat{\text { - }}$ sured at various times after galactose induction. Northern blot analysis of transcripts of an intron-containing gene, the RP51A gene, showed that as early as $1 \mathrm{hr}$ after the transfer to galactose-containing medium, the splicing of this RNA was severely impaired in cells transformed with the GAL-prp9 9 CH2 plasmid (Fig. 3, bottom). Thus, the lethality induced by the prp $9 \triangle C H 2$ allele is a consequence of a splicing defect.

The dominant lethal phenotype observed with the $\mathrm{CH} 2$ deletion mutant suggests that the PRP9 protein has at least two functional domains, because a dominant lethal phenotype may be viewed as the result of a competition between an inactive protein that retains one function and the active protein that contains at least two

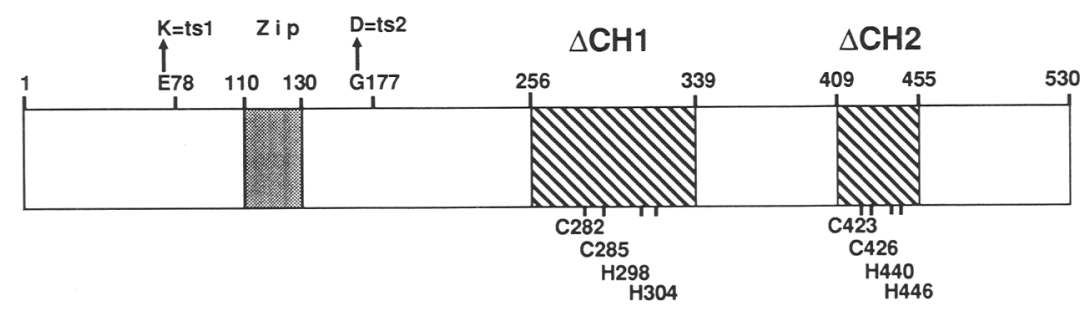

Figure 1. The PRP9 protein. Positions and changes corresponding to the prp9-1 (ts1) and prp9-2 (ts2) mutations are indicated, as well as the location of the deletion mutants $\mid \Delta \mathrm{CH} l$ and $\Delta \mathrm{CH} 2$, hatched boxes) and the conserved residues in the zinc fingers. A putative leucine zipper motif (Zip) is indicated. 
Legrain et al.

Table 1. The prp9 $9 \mathrm{CH} 2$ mutant exhibits a dominant lethal phenotype in a prp9-1 strain

\begin{tabular}{lc}
\hline Plasmid & Efficiency \\
\hline pEMBLYe31 (high copy) & $>1500$ \\
PRP9 & 500 \\
prp9 9 CH1 & $>1500$ \\
prp9 94 CH2 & 3 \\
YCp50 (low copy) & 600 \\
PRP9 & $>1000$ \\
prp9 9 CH1 & 600 \\
prp9 $9 H 2$ & $7+40$ small \\
prp9-1, $\triangle C H 2$ & $>1000$ \\
\hline
\end{tabular}

Cells were transformed and grown at $25^{\circ} \mathrm{C}$. Transformation efficiency is expressed as the number of colonies obtained with 1 $\mu \mathrm{g}$ of plasmid DNA.

functional sites (Herskowitz 1987). One of the interactions of the PRP9 $\triangle \mathrm{CH} 2$ protein that remains unaltered involves the region containing the mutated temperaturesensitive residues, because the dominant lethal phenotype is observed in prp9-1 and prp9-2 cells but not in isogenic wild-type cells. The SPP91 protein is a likely candidate as a PRP9 protein partner, because the spp91-1 allele was isolated as a suppressor of the prp9-1 mutation.

PRP9 and SPP91 proteins interact through the aminoterminal domain of the PRP9 protein

To analyze the possible interactions of the PRP9 protein, we used the two-hybrid system (Fields and Song 1989; Chien et al. 1991), which scores for in vivo interactions

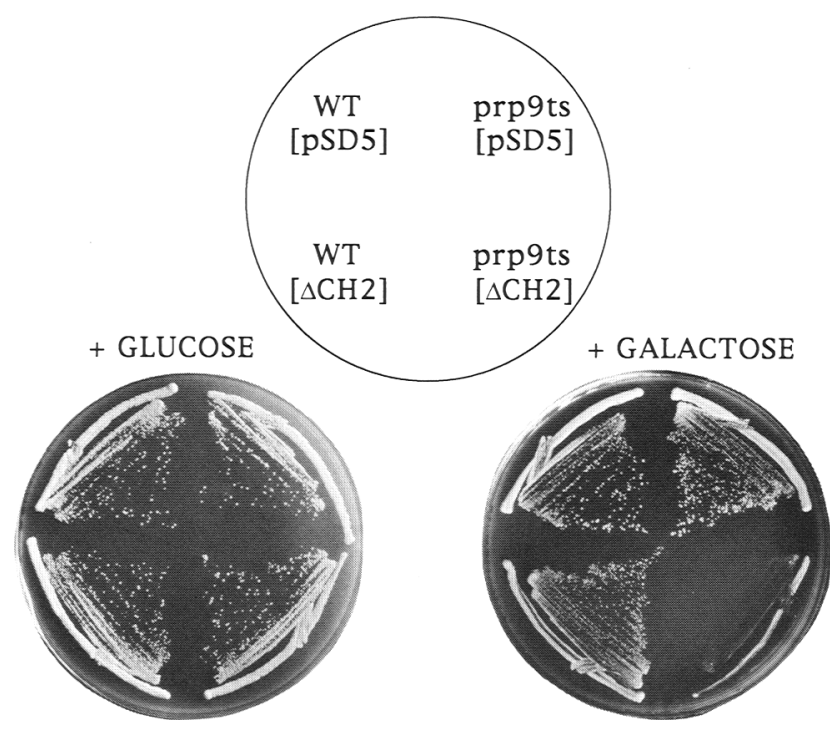

Figure 2. Growth phenotype of the prp $9 \Delta \mathrm{CH} 2$ mutant. Cells were streaked on glucose- or galactose-containing medium and grown at $25^{\circ} \mathrm{C}$. The wild-type (WT) and prp9-1 (prp9ts) strains are isogenic (Chapon and Legrain 1992) and were transformed with the prp $9 \Delta \mathrm{CH} 2(\Delta \mathrm{CH} 2)$ plasmid or the pLGSD5 (pSD5) control vector.

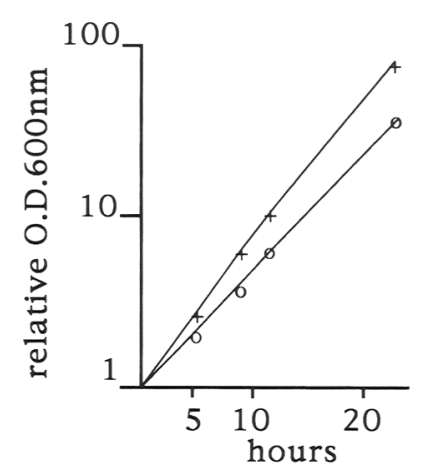

\section{pLGSD5}
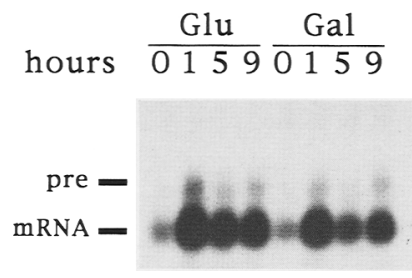

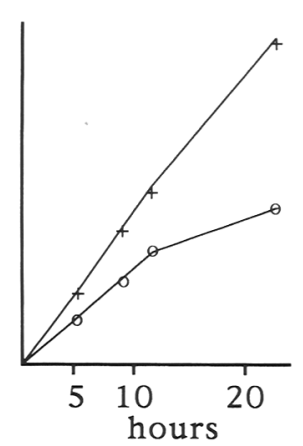

$\operatorname{prp} 9 \Delta \mathrm{CH} 2$
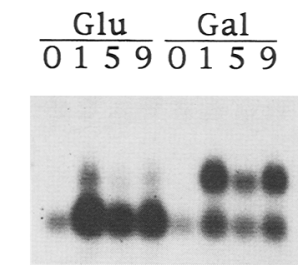

Figure 3. Splicing defect associated with the dominant lethal phenotype of the prp9 $9 \mathrm{CH} 2$ mutant. prp9-1 cells were transformed with plasmids pLGSD5 (left) or prp $9 \Delta \mathrm{CH} 2$ (right). (Top) Growth curves in glucose $(+1$ - or galactose $(O)$ - containing media. (Bottom) Northern analysis was carried out with a RP51A gene probe on RNAs prepared from cells after transfer $(0,1,5$, and $9 \mathrm{hr}$ ) to glucose- or galactose-containing media. The positions of the RP51A pre-mRNA (pre) and mRNA are indicated.

between two proteins overproduced in S. cerevisiae. In this assay, two proteins are fused to the DNA-binding domain and to the activation domain of the yeast transcriptional factor GAL4, respectively. An interaction between these proteins brings together the two GAL4 domains, allowing the formation of a functional GAL4 complex, which activates the expression of a lac $Z$ reporter gene. The interaction of the PRP9 and SPP91 proteins was assayed, in the two possible combinations, pGAD2F:PRP9/pMA424:SPP91 and conversely (Fig. 4A). As indicated by the blue color of the colonies, the SPP91 protein interacts strongly either with the PRP9 protein or the PRP9 $\mathrm{CH} 2$ protein. In contrast, the prp9-1 mutation severely reduces the interaction between the PRP9 and SPP91 proteins, which becomes barely detectable.

This observation led us to test whether the spp91-1 mutation suppresses the prp9-1 phenotype by restoring the interaction between the PRP9-1 and SPP91-1 mutant proteins (Fig. 5). At $30^{\circ} \mathrm{C}, \beta$-galactosidase activities in cells transformed with the PRP9 and SPP91 hybrid constructs varied between 50 and 100 units. These activities were reduced to nearly background levels by the prp $9-1$ mutation. $\beta$-Galactosidase activity was increased by the spp91-1 mutation in combination A / $~ 5$ units compared with $<1$ unit for the PRP9-1 and SPP91 interaction), although no effect of this mutation was detectable in the other combination. Because the prp9-1 mutant exhibits a temperature-sensitive phenotype, these experiments 

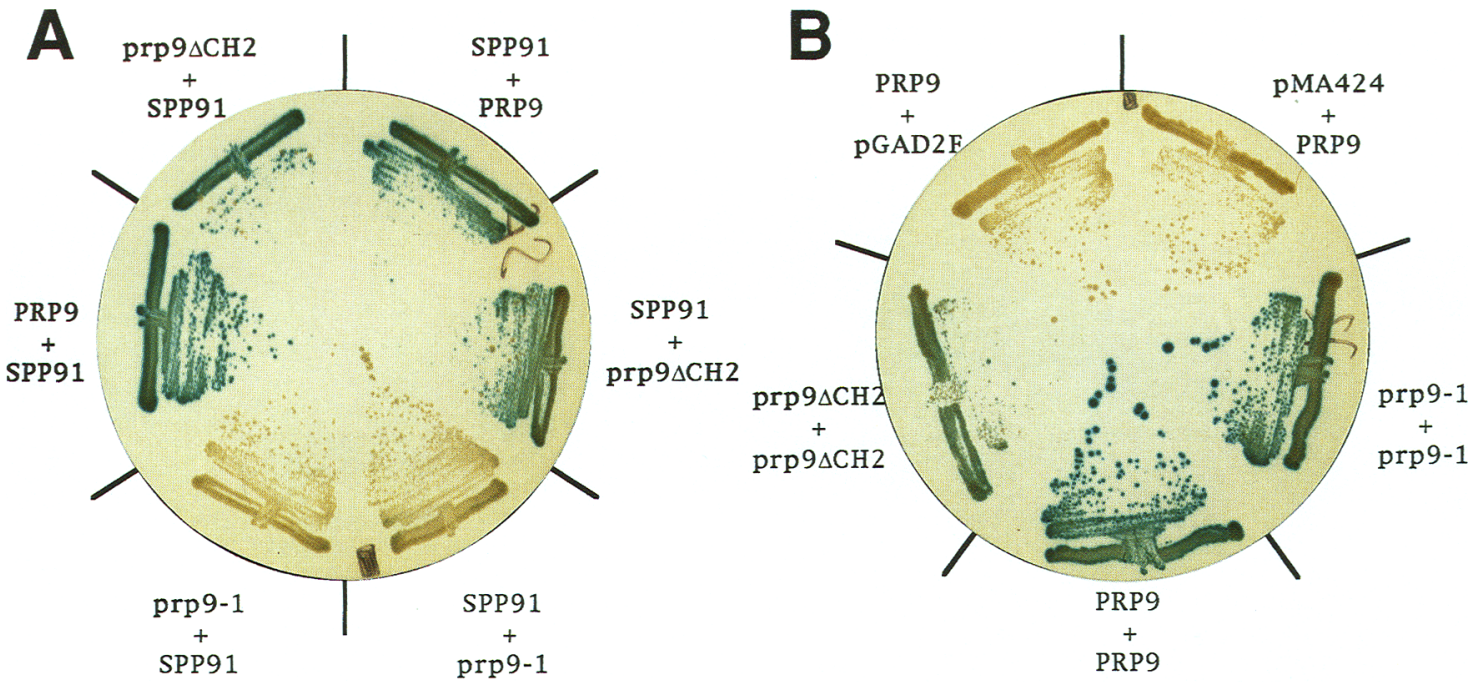

Figure 4. In vivo dimerization of PRP9 and SPP91 proteins and homodimerization of the PRP9 protein. GGY1::171 cells were transformed with a pGAD2F derivative plasmid [GAL4-activating domain (bottom line)] and a pMA424 derivative plasmid [GAL4 DNA-binding domain; (top line)] harboring PRP9, PRP9-1, PRP9 $\triangle \mathrm{CH2}$, or SPP91 hybrid proteins. (A) Interaction between the PRP9 and SPP91 proteins (PRP9-SPP91 dimer). The heterodimerization assay is presented for the two combinations, with PRP9, PRP9-1, and PRP9 $\triangle \mathrm{CH} 2$ proteins produced from the pGAD2F plasmid and SPP91 protein from the pMA424 plasmid and conversely. (B) Homodimerization of the PRP9 protein. Two negative controls with pGAD2F or pMA424 vectors are included.

were also performed with cells grown at $22^{\circ} \mathrm{C}$ (Fig. 5, right panel). At this temperature, PRP9 and SPP91 interaction still results in high levels of $\beta$-galactosidase activity, which is reduced in the presence of the prp9-1 mutation. The levels of $\beta$-galactosidase activity are consistently lower at $22^{\circ} \mathrm{C}$ than at $30^{\circ} \mathrm{C}$, which is also seen for the wild-type GAL4 protein (data not shown). The restoration of high levels of $\beta$-galactosidase activity by the spp91-1 mutation, however, is more pronounced than at $30^{\circ} \mathrm{C}$ (Fig. 5, cf. PRP9-1/SPP91 and PRP9-1/ SPP91-1 interactions). Similar data were also obtained with the prp9-2 mutation (data not shown), consistent with the observation that the spp91-1 mutation also suppresses this temperature-sensitive mutation /Chapon and Legrain 1992), which maps to residue 177 (see Materials and methods; Fig. 1). These results clearly demonstrate that the positions corresponding to the prp9-1 and prp9-2 mutations, which are located on the aminoterminal domain of the PRP9 protein, contribute to the binding between the PRP9 and SPP91 proteins.

\section{The PRP9 protein homodimerizes through a domain containing the CH2 motif independent of the SPP91-binding domain}

Experiments utilizing the two-hybrid system also established that the PRP9 protein has the capacity to form homodimers (Figs. 4B and 6A). The prp9-1 and prp9-2 mutations did not affect homodimerization, whereas deletion of the $\mathrm{CH}$ l domain completely abolished dimer formation. Deletion of the $\mathrm{CH} 2$ domain reduced the homodimerization efficiency by a factor of 4 . Overproduction of the PRP9 $\mathrm{CH} 2$ protein has some detrimental effects on the cells, as judged by colony size and the ap- pearance of white revertant colonies (see also Fig. 4A). In addition, fusion proteins were also produced from the point mutants in the $\mathrm{CH} 2$ motif at the cysteine- and histidine-conserved residues (Legrain and Choulika 1990). The $\beta$-galactosidase activities measured with these hybrid proteins were reduced by at least one order of magnitude, this effect being more pronounced with the cysteine mutations, demonstrating that the $\mathrm{CH} 2$ point mutations severely affect PRP9 protein homodimerization.

The effect of the mutations in the $\mathrm{CH} 1$ or $\mathrm{CH} 2$ regions of the PRP9 protein on the interaction with the SPP91 protein was also tested (Table 2). Neither the $\mathrm{CH} 2$ deletion nor the $\mathrm{CH} 2$ point mutations significantly affect binding to the SPP91 protein (Table 2). The $\beta$-galactosidase activities differed at the most by a factor of two from the values measured for the wild-type PRP9 hybrid proteins. In contrast, the PRP9 $\triangle \mathrm{CH} 1$ protein is unable to bind the SPP91 protein. Because the PRP9 $\triangle \mathrm{CH} 1$ protein is also unable to homodimerize and the prp $9 \Delta C H 1 \mathrm{mu}-$ tant does not exhibit a dominant lethal phenotype, the inability to bind the SPP91 protein probably results from a large alteration of the protein structure, which inactivates the PRP9 $\triangle \mathrm{CH} 1$ protein. These experiments establish that the $\mathrm{CH} 2$ motif is an essential element for the PRP9 protein dimerization but not for the binding to the SPP91 protein.

The CH2 motif of the PRP9 protein is required for interaction with an additional factor

Because the PRP9 $\triangle \mathrm{CH} 2$ mutant protein binds the SPP91 protein (Table 2), the dominant lethal phenotype caused by the expression of the prp9ACH2 allele in a prp9-1 or 
Legrain et al.

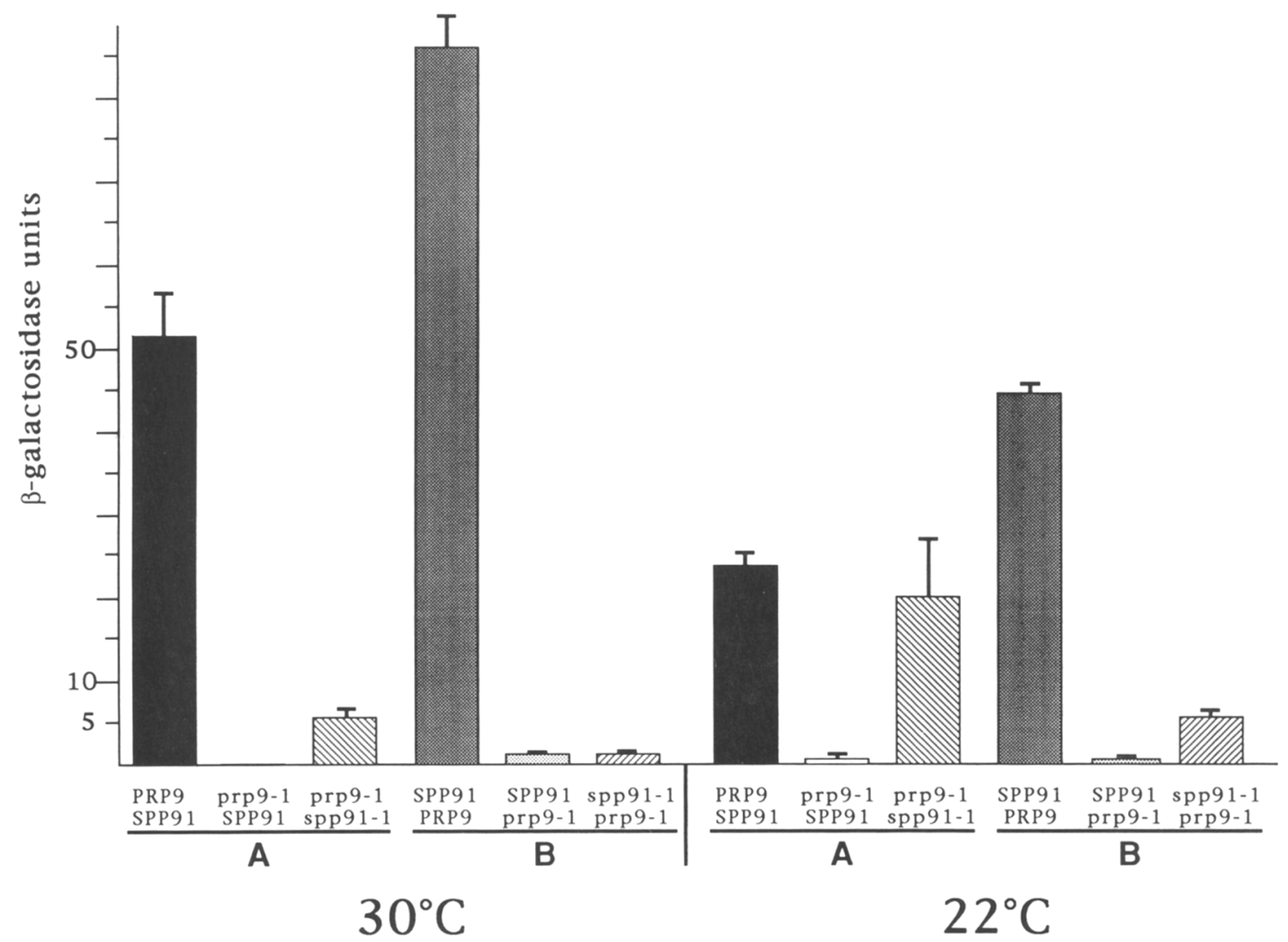

Figure 5. Analysis of interactions between PRP9 and SPP91 proteins. Y526 cells were transformed with two plasmids derived from pGAD2F (top line) or pMA424 (bottom line), respectively. Cells were grown at $30^{\circ} \mathrm{C}$ or $22^{\circ} \mathrm{C}$. The two combinations $(A$ and $B)$ are shown for each interaction. Error bars are indicated (see Materials and methods).

prp9-2 background could result from titration of the SPP91 protein and the reduced homodimerization ability of the prp $9 \Delta \mathrm{CH} 2$ protein. prp9-1 Cells transformed with the prp $9 \Delta \mathrm{CH} 2$ plasmid may also contain the heterologous PRP9-1/PRP9 $\triangle \mathrm{CH} 2$ dimers, in addition to PRP9$\triangle \mathrm{CH} 2 / \mathrm{PRP} 9 \mathrm{CH} 2$ and PRP9-1/PRP9-1 homodimers. Through the use of the two-hybrid system, the PRP9$\triangle \mathrm{CH} 2$ protein dimerized with PRP9 and PRP9-1 proteins with wild-type efficiencies (Fig. 6B). Similarly, the $\mathrm{CH} 2$ point mutants form heterologous dimers with the PRP9 or the PRP9-1 protein as efficiently as the PRP9 $\triangle \mathrm{CH} 2$ protein (data not shown). These results strongly suggest that heterologous dimers can form in cells either transformed with the PRP9ACH2 or the $\mathrm{CH} 2$ point mutant plasmids. Thus, the observed dominant lethal phenotype of the PRP9 $\triangle \mathrm{CH} 2$ mutant probably does not result from the reduced ability of the corresponding protein to homodimerize, but from the loss of an additional PRP9 function that is associated with the $\mathrm{CH} 2$ domain.

The PRP9 protein acts in the spliceosome assembly after the formation of the U1 snRNP-pre-mRNA commitment complex

The specific step at which the PRP9 protein is required before the binding of the U2 snRNP is not established. We investigated the function of the PRP9 protein in the spliceosome assembly in further detail by in vitro assays. Anti-PRP9 antibodies were raised and used either to inhibit splicing reactions or to immunodeplete splicing extracts. These reactions were analyzed by electrophoresis in non-denaturing conditions, which resolves the commitment complexes (containing the U1 snRNP) from the later complexes (Fig. 7, lanes 1-4; Seraphin and Rosbash 1989|. Preincubation of a splicing extract with anti-PRP9 antibodies prior to the addition of the pre-mRNA specifically inhibits the spliceosome formation (lanes 6-12, cf. with lane 5). Concomitantly with the decrease of spliceosome formation, accumulation of commitment complexes was observed. To determine whether the PRP9 protein is required for the formation of the commitment complexes, immunodepletion experiments were performed with anti-PRP9 antibodies. Immunodepletion of the PRP9 protein from splicing extracts prevented the formation of spliceosomes, whereas the commitment complexes accumulated (lanes 13-18). These results establish that the PRP9 protein acts after the binding of the U1 snRNP to the pre-mRNA and is required for the binding of the U2 snRNP to this commitment complex.

\section{Discussion}

In S. cerevisiae, the PRP9 protein is required for U2 


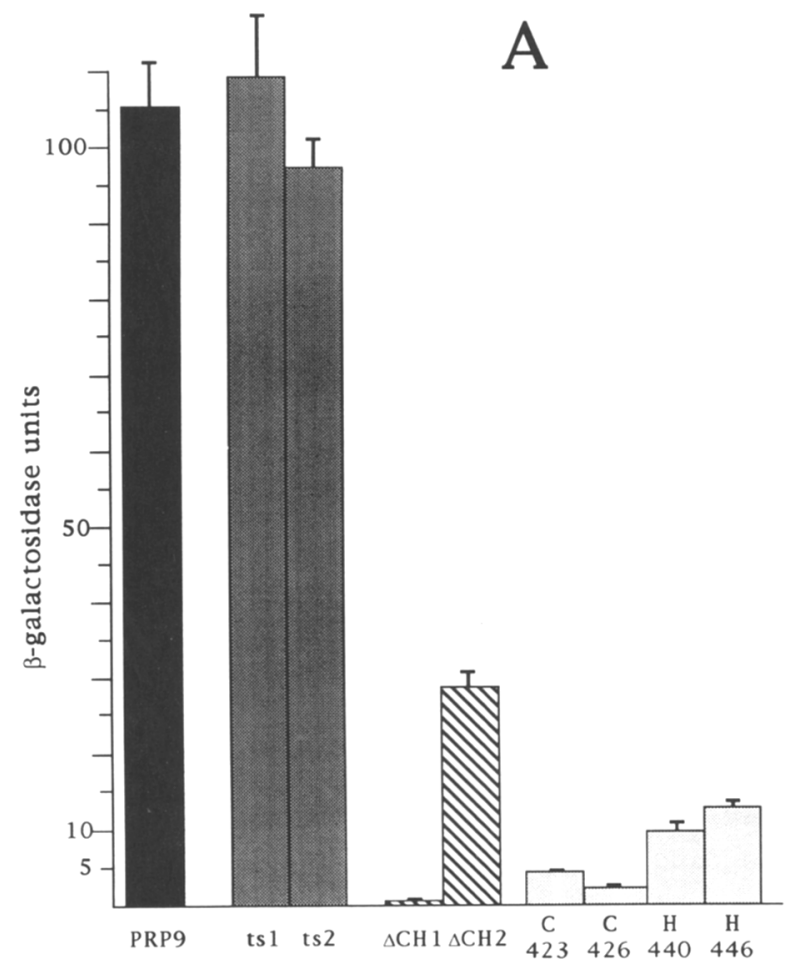

snRNP binding to the spliceosome but is not tightly associated with this snRNP. The interaction of this factor with the pre-mRNA, however, depends on the integrity of the U2 snRNA (Abovich et al. 1990). In HeLa cell extracts, anti-PRP9 antibodies cross-react with a protein that is a component of the U2 17S snRNP (Behrens et al.

Table 2. Mutations in the PRP9 CH2 motif do not interfere with the binding to the SPP91 protein

\begin{tabular}{lr}
\hline & $\begin{array}{c}\beta \text {-Galactosidase } \\
\text { activity (units) }\end{array}$ \\
\hline $\begin{array}{c}\text { Combination A } \\
\text { (the SPP91 gene in the pGAD2F plasmid) }\end{array}$ & \\
PRP9 & $65.9 \pm 4.2$ \\
PRP9DCH1 & $1.3 \pm 0.3$ \\
PRP9DCH2 & $63.9 \pm 3.4$ \\
PRP9-C423 & $29.3 \pm 5.6$ \\
PRP9-C426 & $26.2 \pm 1.1$ \\
PRP9-H440 & $31.8 \pm 2.2$ \\
PRP9-H446 & $44.6 \pm 2.1$ \\
Combination B & \\
(the SPP91 gene in the pMA424 plasmid) & $56.4 \pm 3.7$ \\
PRP9 & \\
PRP9DCH1 & $<0.1$ \\
PRP9DCH2 & $19.4 \pm 4.6$ \\
PRP9-C423 & $61.3 \pm 3.9$ \\
PRP9-C426 & $31.9 \pm 1.8$ \\
PRP9-H440 & $51.7 \pm 4.1$ \\
PRP9-H446 & $67.4 \pm 3.6$ \\
\hline
\end{tabular}

Y526 cells were transformed with the indicated plasmids and assayed for $\beta$-galactosidase activity.

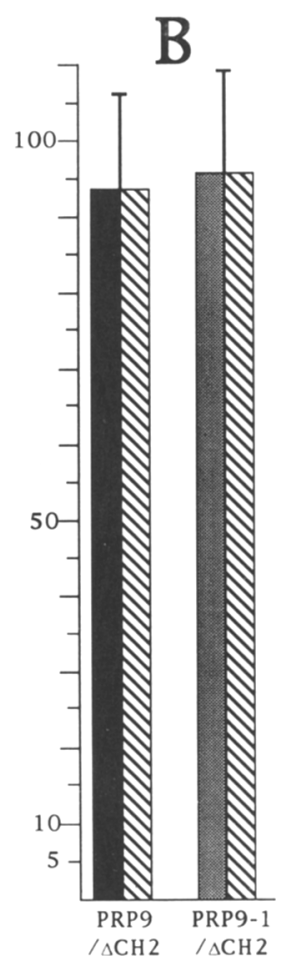

Figure 6. Homodimer formation between PRP9 proteins. (A) PRP9 protein homodimers. Wild-type (solid bar), heat sensitive (dark shaded bar), $\mathrm{CH} 2$ point mutants (light shaded bar), and deletion mutants (hatched bars) homodimers are presented. $(B)$ Heterologous PRP9 dimers. The dimers between the $\mathrm{PRP} 9 \triangle \mathrm{CH} 2$ protein (produced from a pGAD2F plasmid) and the wild-type PRP9 or the PRP9-1 proteins are presented. Error bars are indicated (see Materials and methods). 1993a). Here, we establish that the PRP9 protein acts after the formation of the commitment complexes. Thus, it is very likely that the PRP9 protein contributes to the binding of the U2 snRNP to the pre-mRNA/U1 snRNP complex, probably in conjunction with several additional proteins. In higher eukaryotes, the U2AF, SC35, ASF/SF2, SF1, and SF3 proteins /Ge et al. 1991; Krainer et al. 1991; Kramer and Utans 1991; Fu and Maniatis 1992a; Zamore et al. 1992) are also implicated in this step, but little is known concerning their sequential requirement (Bennett et al. 1992a). In addition, some heterogenous nuclear RNPs (hnRNPs) could also be involved in this process (Bennett et al. 1992b). Recently, further purification of the SF3 activity has led to the characterization of a factor, SF3a, required for the prespliceosome assembly, which contains three protein components, including the PRP9 homolog (R. Brosi and A. Krämer, pers. comm.).

Several proteins, such as those mentioned above, are required for the binding of the $\mathrm{U} 2$ snRNP to the commitment complexes; these proteins may interact together and play a role in prespliceosome formation as a multimolecular complex. Here, we show evidence for such protein-protein interactions between the PRP9 and SPP91 splicing factors. Deletion of the $\mathrm{CH} 2$ region of the PRP9 protein leads to a dominant lethal phenotype in prp9-1 and prp9-2 strains. The restriction of the expression of the dominant lethal phenotype to prp9-1 or prp9-2 mutants and the isolation of $s p p 91-1$ as a suppressor of these mutations strongly suggested that the SPP91 and PRP9 proteins interact. We confirmed this interaction by use of the two-hybrid system (Fields and Song 
Figure 7. Inhibition of spliceosome formation and immunodepletion of splicing extracts with anti-PRP9 antibodies. In vitro splicing reactions performed with labeled pre-mRNA were analyzed by native gel electrophoresis (Seraphin and Rosbash 1989). (Left; lanes 1-4) Kinetic analysis of splicing complexes formation. (Middle; lanes 5-12) Inhibition of splicing reactions with $32 \mu \mathrm{g}$ of preimmune serum immunoglobulins (lane 5) or various amounts of anti-PRP9 immunoglobulins [(lanes $6-12) 32,16,8,4,2,1$, and $0.5 \mu \mathrm{g}$, respectively)]. (Right; lanes 13-18) Immunodepletion of a splicing extract with various amounts of preimmune [(lane 13) $48 \mu$ l] or anti-PRP9 [(lanes 14-18) 48, 24, 12, 6 , and $3 \mu \mathrm{l}$, respectively] sera. In lanes $5-18$, splicing reactions were carried out for $20 \mathrm{~min}$. Commitment complexes $(\mathrm{CC})$ and later splicing complexes $(\mathrm{SP})$ are indicated at left.

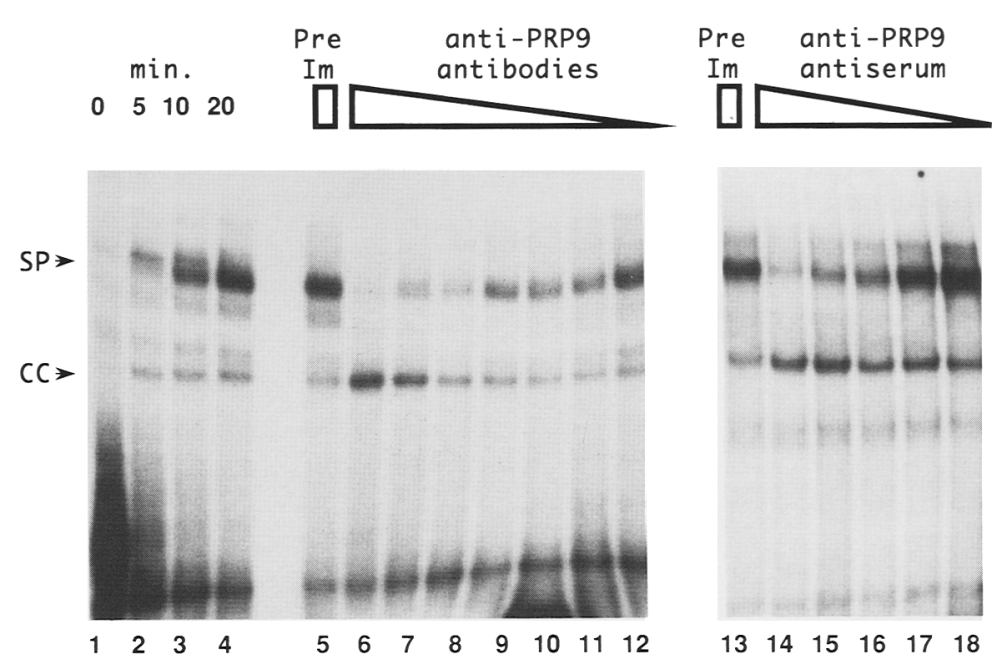

1989; Chien et al. 1991). To our knowledge, this is the first demonstration of a protein-protein interaction between two splicing factors. The binding of U2AF to its $35-\mathrm{kD}$-associated protein has been reported, however the $35-\mathrm{kD}$ protein is not required for in vitro splicing reactions (Zhang et al. 1992). The prp9-1 and prp9-2 mutations identify two residues important for the binding of the SPP91 protein. They are located on flanking sides of a putative leucine zipper structure, a classical dimerization motif (Landschulz et al. 1988). No such motif, however, is present in the SPP91 sequence. Recently, the SPP91 protein was shown to be identical to the PRP21 protein, a splicing factor not tightly associated with any snRNP in the absence of spliceosomes but required for the formation of U2 snRNP-pre-mRNA complexes (J. Arenas and J. Abelson, pers. comm.). Interactions between PRP proteins have been suggested, on the basis of genetic evidence such as synthetic lethality, suppression of heat-sensitive mutations by overexpression of a wildtype gene, or selection of second-site suppressors (Last et al. 1987; Jamieson et al. 1991; Strauss and Guthrie 1991), but in none of these cases have direct interactions been demonstrated. Dominant lethal mutants have also been reported for a $\mathrm{U} 2$ snRNA mutant in the branchpoint binding sequence (Miraglia et al. 1991) and also for a prp16 mutant (Schwer and Guthrie 1992).

The homodimerization of the PRP9 protein requires intact $\mathrm{CH} 1$ and $\mathrm{CH} 2$ regions. The $\mathrm{PRP} 9 \Delta \mathrm{CH} 2$ protein retains a reduced ability to homodimerize, which may be attributed to the presence of the $\mathrm{CH} 1$ domain. The $\mathrm{CH} 1$ and $\mathrm{CH} 2$ regions of the PRP9 protein, as well as those found in three other splicing factors, the yeast PRP6, PRP11 proteins and the human U1C protein, are loosely related to those found in zinc finger proteins (Legrain and Choulika 1990). The canonical TFIIIA zinc fingers are involved in DNA and RNA binding (Darby and Joho 1992; Theunissen et al. 1992), but more generally, zinc fingers are considered as basic structural protein elements (Kaptein 1991). Our results strongly suggest that the $\mathrm{CH} 2$ motif may be directly involved in the ho- modimerization process but not necessarily as sites of direct contact.

The PRP9 protein behaves as a modular protein with two independent domains. The interactions between the various PRP9 and SPP91 proteins are summarized in Figure 8 . The heat-sensitive phenotype of the prp9-1 mutant is attributable to a weak interaction of the PRP9 protein with the SPP91 protein. The PRP9 $\triangle \mathrm{CH} 2$ protein homodimerization is reduced, but heterologous dimers, e.g., prp9-1/PRP9 $\Delta \mathrm{CH} 2$, form normally. The inability of

\section{Proteins Predicted interactions Phenotype}

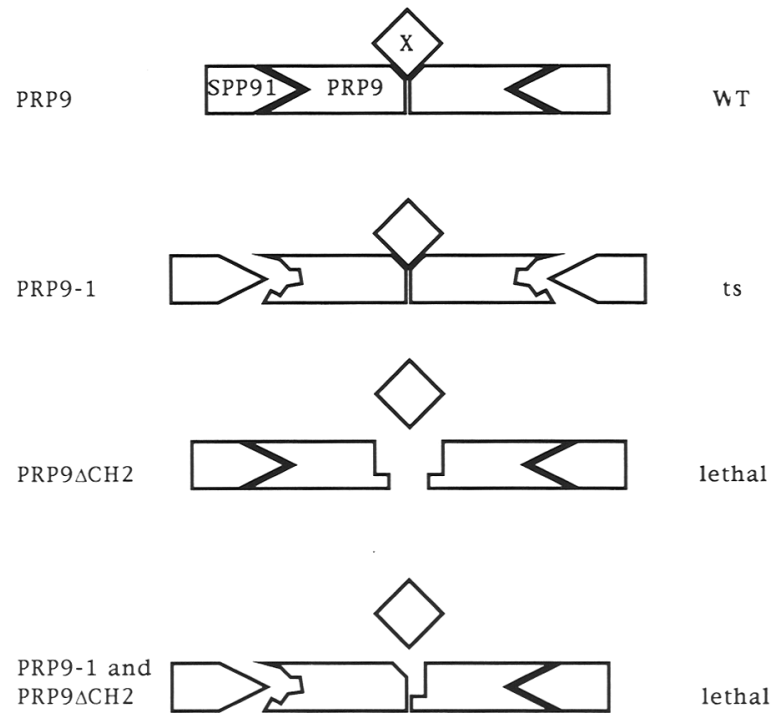

Figure 8. Model for the identified and predicted interactions of the PRP9 protein. The existence of an unidentified X factor is predicted by the observation of the dominant lethal phenotype of the prp $9 \triangle \mathrm{CH} 2$ mutant and the results of binding assays (see Discussion). 
the PRP9-1/PRP9 $\triangle \mathrm{CH} 2$ dimer to bind the SPP91 protein through the PRP9-1 monomer cannot account for the dominant lethal phenotype because the prp9-1 mutant only displays a temperature-sensitive phenotype. These results indicate that the dominant lethal phenotype of the PRP9 $\triangle \mathrm{CH} 2$ mutant does not result from a lack of homodimerization with the PRP9-1 protein but, rather, that the PRP9-1/PRP9 $\triangle \mathrm{CH} 2$ dimer is not functional. Therefore, we propose that PRP9 homodimers bind an unknown factor (Fig. 8, X factor). PRP9-1/PRP9 $\triangle \mathrm{CH} 2$ and PRP9 $\Delta \mathrm{CH} 2 / \mathrm{PRP} 9 \Delta \mathrm{CH} 2$ dimers cannot bind the $\mathrm{X}$ factor and are defective. Because the PRP9 $\Delta \mathrm{CH} 2$ molecules bind the SPP91 protein with a much higher efficiency than the PRP9-1 molecules, PRP9-1/PRP9 $\triangle \mathrm{CH} 2$ and PRP9 $\Delta \mathrm{CH} 2 / \mathrm{PRP} 9 \Delta \mathrm{CH} 2$ dimers will titrate out the SPP91 protein from the PRP9-1/PRP9-1 dimers, leading to the lethal phenotype. In contrast, the $\mathrm{CH} 2$ point mutants, which do not exhibit a dominant lethal phenotype, may form functional heterologous dimers with the PRP9-1 protein.

Several suggestions as to the identity of the $\mathrm{X}$ factor can be proposed. The U2 snRNP itself might bind to the PRP9 protein by either protein-protein and/or proteinRNA interactions. The presence of zinc finger-related structures in the homodimerization domain of the PRP9 protein is suggestive of a binding to nucleic acids, for example, to the U2 snRNA. The U1C protein, however, contains a similar domain that is involved in the binding to the U1 snRNP, but this binding is probably mediated through protein-protein interactions between U1-70K and U1C proteins (Nelissen et al. 1991). Similarly, the X factor could be a protein associated with the U2 snRNP. No such protein has yet been identified in yeast.

The PRP9/SPP91 complex may allow the bridging between U1 and U2 snRNPs in the splicing complexes. It is probable that the SPP91 protein also binds another splicing factor. In addition to PRP9 and SPP91 proteins, other splicing factors, such as PRP5 and PRP1l proteins (Chang et al. 1988; Dalbadie-McFarland and Abelson 1990), are required early in the spliceosome assembly pathway. Recently, we have shown that the PRP11 protein is associated with the PRP9/SPP9l complex (P. Legrain and C. Chapon, unpubl.). Thus, a multimolecular complex of splicing factors may be implicated in the formation of the U1 and U2 snRNP-containing splicing complex.

\section{Materials and methods}

Yeast strains and manipulation

Yeast media were prepared and genetic manipulations were performed as described (Rose et al. 1990). The wild-type strains, MGD353-13D (MATa ura3-52 trp1-289 leu2-3, -112 ade2 arg4) and MGD353-46D (MATa ura3-52 trp1-289 leu2-3, -112 his341 cyhR) and their prp9-1 counterparts, Cyl05 and Cy103, respectively, have been described previously (Chapon and Legrain 1992). A temperature-sensitive mutant, ts 200 , was isolated during a search for conditional splicing mutants and identified as a prp9 allele (Vijayraghavan et al. 1989). We renamed this mutant allele, prp9-2 because another temperature-sensitive allele, prp9-1, had been characterized previously (Legrain et al. 1991). Strains GGY1::171 (Agal4 Agal80 ura3::GAL1-lacZ his3 leu2) (Gill and Ptashne 1987) and Y526 (Agal4 Agal80 ura3::GAL1lacZ his3 leu2 $\operatorname{trp} 1$ ) were provided by $M$. Werner (CEA, France).

\section{Characterization of the prp9-2 mutation}

The prp9-2 mutation was mapped by plasmid repair, and the mutated DNA was cloned by PCR and sequenced. A single mutation which converts the glycine residue at position 177 into an aspartate residue, was found. The temperature-sensitive phenotype caused by this change was confirmed by in vitro mutagenesis of the wild-type $P R P 9$ gene.

\section{Plasmid construction}

Molecular biology manipulations were performed as described (Sambrook et al. 1989). The plasmid pPL5 (Legrain et al. 1991), which contains the PRP9 gene, was used to derive the $\triangle \mathrm{CH} 1$ and $\triangle \mathrm{CH} 2$ deletions, by digestion and religation of two Sall sites introduced by in vitro mutagenesis at positions indicated by the corresponding amino acid residues in Figure 1. The GALprp $9 \Delta C H 2$ plasmid contains a PCR-derived prp $9 \Delta C H 2$ DNA fragment cloned at the BamHI site of the plasmid pLGSD5, downstream of the GAL10 promoter (Guarente et al. 1982). PCR-derived DNA fragments encoding the appropriate PRP9 or SPP91 open reading frames were inserted at the BamHI site of the pGAD2F and pMA424 plasmids (Ma and Ptashne 1987; Chien et al. 1991) and partially sequenced. Six mutations, resulting from PCR mutagenic activity, were found in $>18,000$ nucleotides sequenced. Three additional mutations were found in the nucleotides containing the oligonucleotide primer sequences, giving a rate of error of $\sim 0.5 \%$. These mutations are unlikely to affect the results observed, because both combinations give essentially similar results. The PRP9 $\Delta \mathrm{CH}$ constructs, which did not display any binding activity, were sequenced in toto.

\section{In vivo splicing defect analysis}

Transformed cells were grown at $25^{\circ} \mathrm{C}$ in selective medium lacking uracil and containing $2 \%$ lactate, $2 \%$ glycerol, and $0.05 \%$ glucose. Exponentially growing cells were transferred to glucose $(2 \%)$ - or galactose $(2 \%)$-containing media. Regular dilutions were made to keep the culture exponential (1-3 OD 600 units). Cells were harvested at various times, and RNA was prepared (Pikielny and Rosbash 1985). Northern blot analysis using a RP51A DNA probe detecting both mRNA and premRNA was performed as described previously (Chapon and Legrain 1992).

\section{$\beta$-Galactosidase assays}

Protein-protein interaction in the two-hybrid system can be monitored on plates in the presence of X-gal or in liquid culture by assaying the $\beta$-galactosidase activity present in the cells. Plate assays were performed at $37^{\circ} \mathrm{C}$ with a $3-$ to $5-\mathrm{ml}$ overlay containing $0.5 \%$ agar, $0.5 \mathrm{M}$ phosphate buffer (pH 7.0$) 1 \%$ SDS, $6 \%$ dimethylformamide, and $0.02 \% \mathrm{X}$-gal. Quantitative assays were performed on liquid cultures. Exponentially growing cells were harvested $\left(\sim 1 \mathrm{OD}_{600} / \mathrm{ml}\right)$ and $\beta$-galactosidase assays were performed as described previously except that the incubation temperature was $30^{\circ} \mathrm{C}$ (Legrain and Rosbash 1989). A $\beta$-galactosidase unit corresponds to $10^{3} \times \mathrm{OD}_{420}$ units per minute of reaction for $1 \mathrm{ml}$ of culture at $1 \mathrm{OD}_{600}$ unit. Under these con- 
ditions, cells transformed with a plasmid harboring the GAL4 protein provide $\sim 1000$ (Y526 strain) or 2000 (GGY1::171 strain) units, and the sensitivity of the assay is $\sim 0.1$ unit. Cells transformed with only one of the PRP9- or SPP91-derived plasmids and either the pGAD2F or pMA424 vector contained $<0.5$ unit (e.g., see Fig. 4B). Assays were done in duplicate for three independent transformants. Means of values and standard deviations are indicated.

\section{Preparation of anti-PRP9 antibodies}

A recombinant PRP9 protein deleted for the first 25 amino acid residues was produced in Escherichia coli using the pET3c expression vector (Studier and Moffatt 1986; Rosenberg et al. 1987), gel-purified, and injected into rabbits. These antibodies react, by western blot, with a $65-\mathrm{kD}$ product, identified as the PRP9 protein by use of cells overexpressing the PRP9 gene (Behrens et al. 1993a).

\section{In vitro splicing reaction}

Splicing extract preparation, transcription of the $\Delta 2$ splicing substrate derived from the RP51A gene, and native gel electrophoresis were performed as described (Seraphin and Rosbash 1989). The immunoglobulin fraction from sera was purified by affinity chromatography on protein A-Sepharose. Inhibition of the splicing reaction was performed as follows: $4 \mu \mathrm{l}$ of splicing extract was mixed with various amounts of immunoglobulins for $30 \mathrm{~min}$ at $4^{\circ} \mathrm{C}$. The splicing reactions were initiated by the addition of the $\Delta 2$ substrate in the appropriate buffer and incubations performed under the standard conditions. The immunodepletion experiment was performed as follows: Protein-ASepharose beads were incubated in NET150 buffer (150 mM $\mathrm{NaCl}, 50 \mathrm{~mm}$ Tris- $\mathrm{HCl}$ at $\mathrm{pH} 7.4,0.05 \% \mathrm{NP}-40$ ) with various amounts of serum at $4^{\circ} \mathrm{C}$ for $2 \mathrm{hr}$. After two washes in NET150 buffer, two washes were performed in the splicing extract buffer (Lin et al. 1985). The beads were then incubated for $1 \mathrm{hr}$ at $4^{\circ} \mathrm{C}$ with $8 \mu \mathrm{l}$ of splicing extract. After centrifugation, $4 \mu \mathrm{l}$ of supernatant was removed and used for in vitro splicing reactions.

\section{Acknowledgments}

We are greatly indebted to G. Bordenave for his expertise and help in immunization procedures, to S. Fields and M. Werner for plasmids and strains used for the two-hybrid system and to U. Vijayraghavan for the gift of the prp9-2 strain. We thank J. Arenas, J. Abelson, R. Brosi, and A. Krämer for communicating unpublished results. We also thank G. Chanfreau, A. Jacquier, A. Korman, A. Plessis, and C. Transy for numerous stimulating discussions and for critical reading of the manuscript. Finally, we particularly acknowledge the continuous support and interest of B. Dujon in this work. This work was partly supported by the Université Pierre et Marie Curie and the Centre National de la Recherche Scientifique (URA 1149). F.G. is ATER at the Université Pierre et Marie Curie.

The publication costs of this article were defrayed in part by payment of page charges. This article must therefore be hereby marked "advertisement" in accordance with 18 USC section 1734 solely to indicate this fact.

\section{References}

Abovich, N., P. Legrain, and M. Rosbash. 1990. The yeast PRP6 gene encodes a U4/U6 small nuclear ribonucleoprotein particle (snRNP) protein, and the PRP9 gene encodes a protein required for U2 snRNP binding. Mol. Cell. Biol. 10: 64176425.

Barabino, S.M., B.J. Blencowe, U. Ryder, B.S. Sproat, and A.I. Lamond. 1990. Targeted snRNP depletion reveals an additional role for mammalian U1 snRNP in spliceosome assembly. Cell 63: 293-302.

Behrens, S.E., F. Galisson, P. Legrain, and R. Lührmann. 1993a. Evidence that the $60-\mathrm{KDa}$ protein of the $17 \mathrm{~S}$ U2 small nuclear ribonucleoprotein particle is immunologically and functionally related to the yeast PRP9 splicing factor and is required for the efficient formation of the prespliceosome. Proc. Natl. Acad. Sci. (in press).

Behrens, S.E., K. Tyc, B. Kastner, J. Reichelt, and R. Lührmann. 1993b. Small nuclear ribonucleoprotein (RNP) U2 contains numerous additional proteins and has a bipartite RNP structure under splicing conditions. Mol. Cell. Biol. 13: 307-319.

Bennett, M., S. Michaud, J. Kingston, and R. Reed. 1992a. Protein components specifically associated with prespliceosome and spliceosome complexes. Genes \& Dev. 6: 19862000.

Bennett, M., S. Piñol-Roma, D. Staknis, G. Dreyfuss, and R. Reed. 1992b. Differential binding of heterogeneous nuclear ribonucleoproteins to mRNA precursors prior to spliceosome assembly in vitro. Mol. Cell. Biol. 12: 3165-3175.

Bordonne, R., J. Banroques, J. Abelson, and C. Guthrie. 1990. Domains of yeast U4 spliceosomal RNA required for PRP4 protein binding, snRNP-snRNP interactions, and pre-mRNA splicing in vivo. Genes \& Dev. 4: 1185-1196.

Chang, T.H., M.W. Clark, A.J. Lustig, M.E. Cusick, and J. Abelson. 1988. RNA11 protein is associated with the yeast spliceosome and is localized in the periphery of the cell nucleus. Mol. Cell. Biol. 8: 2379-2393.

Chapon, C. and P. Legrain. 1992. A novel gene, spp91-1, suppresses the splicing defect and the pre-messenger-RNA nuclear export in the prp9-1 mutant. EMBO I. 11: 3279-3288.

Cheng, S.C. and J. Abelson. 1987. Spliceosome assembly in yeast. Genes \& Dev. 1: 1014-1027.

Chien, C.T., P.L. Bartel, R. Sternglanz, and S. Fields. 1991. The two-hybrid system: A method to identify and clone genes for proteins that interact with a protein of interest. Proc. Natl. Acad. Sci. 88: 9578-9582.

Dalbadie-McFarland, G. and J. Abelson. 1990. PRP5: A helicaselike protein required for mRNA splicing in yeast. Proc. Natl. Acad. Sci. 87: 4236-4240.

Darby, M.K. and K.E. Joho. 1992. Differential binding of zinc fingers from Xenopus TFIIIA and p43 to 5S RNA and the 5S RNA gene. Mol. Cell. Biol. 12: 3155-3164.

Fields, S. and O.K. Song. 1989. A novel genetic system to detect protein-protein interactions. Nature 340: 245-246.

Frank, D., B. Patterson, and C. Guthrie. 1992. Synthetic lethal mutations suggest interactions between U5 small nuclear RNA and 4 proteins required for the 2 nd step of splicing. Mol. Cell. Biol. 12: 5197-5205.

Frendewey, D. and W. Keller. 1985. Stepwise assembly of a premRNA splicing complex requires U-snRNPs and specific intron sequences. Cell 42: 355-367.

Fu, X.D. and T. Maniatis. 1992a. The 35-kDa mammalian splicing factor SC35 mediates specific interactions between U1 and U2 small nuclear ribonucleoprotein particles at the $3^{\prime}$ splice site. Proc. Natl. Acad. Sci. 89: 1725-1729.

1992b. Isolation of a complementary DNA that encodes the mammalian splicing factor SC35. Science 256: 535-538.

Ge, H., P. Zuo, and J. Manley. 1991. Primary structure of the human splicing factor ASF reveals similarities with Drosophila regulators. Cell 66: 373-382.

Gill, G. and M. Ptashne. 1987. Mutants of Gal4 protein altered 
in an activation function. Cell 51: 121-126.

Green, M.R. 1991. Biochemical mechanisms of constitutive and regulated pre-mRNA splicing. Annu. Rev. Cell Biol. 7: 559599.

Guarente, L., R.R. Yocum, and P. Gifford. 1982. A GAL10CYCl hybrid yeast promoter identifies the GAL4 regulatory region as an upstream site. Proc. Natl. Acad. Sci. 79: 7410 7414.

Guthrie, C. 1991. Messenger RNA splicing in yeast: clues to why the spliceosome is a ribonucleoprotein. Science 253: 157-163.

Hartwell, L.H., C.S. McLaughlin, and J.R. Warner. 1970. Identification of ten genes that control ribosome formation in yeast. Mol. Gen. Genet. 109: 42-56.

Herskowitz, I. 1987. Functional inactivation of genes by dominant negative mutations. Nature 329: 219-222.

Jamieson, D.J., B. Rahe, J. Pringle, and J.D. Beggs. 1991. A suppressor of a yeast splicing mutation (prp8-1) encodes a putative ATP-dependent RNA helicase. Nature 349: 715-717.

Kaptein, R. 1991. Zinc-finger structures. Curr. Opin. Struct. Biol. 2: 109-115.

Konarska, M.M. and P.A. Sharp. 1986. Electrophoretic separation of complexes involved in the splicing of precursors to mRNAs. Cell 46: 845-855.

Krainer, A.R., A. Mayeda, D. Kosak, and G. Binns. 1991. Functional expression of cloned human splicing factor SF2: Homology to RNA-binding proteins, Ul 70K, and Drosophila splicing regulators. Cell 66: 383-394.

Kramer, A. and U. Utans. 1991. Three protein factors (SF1, SF3, and U2AF) function in pre-splicing complex formation in addition to snRNPs. EMBO I. 10: 1503-1509.

Landschulz, W.H., P.F. Johnson, and S.L. McKnight. 1988. The leucine zipper: a hypothetical structure common to a new class of DNA binding proteins. Science 240: 1759-1764.

Last, R.L., J.R. Maddock, and J.J. Woolford. 1987. Evidence for related functions of the RNA genes of Saccharomyces cerevisiae. Genetics 117: 619-631.

Legrain, P. and A. Choulika. 1990. The molecular characterization of PRP6 and PRP9 yeast genes reveals a new cysteine/ histidine motif common to several splicing factors. EMBO I. 9: 2775-2781.

Legrain, P. and M. Rosbash. 1989. Some cis- and trans-acting mutants for splicing target pre-mRNA to the cytoplasm. Cell 57: 573-583.

Legrain, P., B. Seraphin, and M. Rosbash. 1988. Early commitment of yeast pre-mRNA to the spliceosome pathway. Mol. Cell. Biol. 8: 3755-3760.

Legrain, P., C. Chapon, E. Schwob, R. Martin, M. Rosbash, and B. Dujon. 1991. Cloning of the two essential yeast genes, PRP6 and PRP9, and their rapid mapping, disruption and partial sequencing using a linker insertion strategy. Mol. Gen. Genet. 225: 199-202.

Liao, X.C., J. Tang, and M. Rosbash. 1993. An enhancer screen identifies a gene that encodes the yeast Ul snRNP A protein; implications for snRNP protein function in pre-mRNA splicing. Genes \& Dev. 7: 419-428.

Lin, R.J., A.J. Newman, S.C. Cheng, and J. Abelson. 1985. Yeast mRNA splicing in vitro. J. Biol. Chem. 260: 14780-14792.

Ma, J. and M. Ptashne. 1987. A new class of yeast transcriptional activators. Cell 51: 113-119.

Michaud, S. and R. Reed. 1991. An ATP-independent complex commits pre-messenger-RNA to the mammalian spliceosome assembly pathway. Genes \& Dev. 5: 2534-2546.

Miraglia, L., S. Seiwert, A.H. Igel, and M. Ares 1991. Limited functional equivalence of phylogenetic variation in small nuclear RNA: Yeast U2 RNA with altered branchpoint com- plementary inhibits splicing and produces a dominant lethal phenotype. Proc. Nat1. Acad. Sci. 88: 7061-7065.

Moore, M.J., C.C. Query, and P.A. Sharp. 1993. Splicing of precursors to messenger RNAs by the spliceosome. In The RNA world (ed. R. Gesteland and J. Atkins), pp. 303-357. Cold Spring Harbor Laboratory Press, Cold Spring Harbor, New York.

Nelissen, R.L., V. Heinrichs, W.J. Habets, F. Simons, R. Lührmann, and V.W. van. 1991. Zinc finger-like structure in U1specific protein $\mathrm{C}$ is essential for specific binding to $\mathrm{U} 1 \mathrm{sn}$ RNP. Nucleic Acids Res. 19: 449-454.

Pikielny, C.W. and M. Rosbash. 1985. mRNA splicing efficiency in yeast and the contribution of nonconserved sequences. Cell 41: 119-126.

Pikielny, C.W., B.C. Rymond, and M. Rosbash. 1986. Electrophoresis of ribonucleoproteins reveals an ordered assembly pathway of yeast splicing complexes. Nature 324: 341-345.

Rose, M.D., F. Winston, and P. Hieter. 1990. Methods in yeast genetics: A laboratory course manual. Cold Spring Harbor Laboratory Press, Cold Spring Harbor, New York.

Rosenberg, A.H., B.N. Lade, D.S. Chui, S.W. Lin, J.J. Dunn, and F.W. Studier. 1987. Vectors for selective expression of cloned DNAs by T7 RNA polymerase. Gene 56: 125-135.

Rymond, B.C. and M. Rosbash. 1992. Yeast pre-mRNA splicing. In The molecular and cellular biology of the yeast Saccharomyces (ed. E.W. Jones J.R. Pringle, and J.R. Broach), pp. 143-192. Cold Spring Harbor Laboratory Press, Cold Spring Harbor, New York.

Sambrook, J., E.F. Fritsch, and T. Maniatis. 1989. Molecular cloning: A laboratory manual. Cold Spring Harbor Laboratory Press, Cold Spring Harbor, New York.

Scherly, D., W. Boelens, N.A. Dathan, W.J. van Venrooij, and I.W. Mattaj. 1990. Major determinants of the specificity of interaction between small nuclear ribonucleoproteins U1A and U2B" and their cognate RNAs. Nature 345: 502-506.

Schwer, B. and C. Guthrie. 1992. A dominant negative mutation in a spliceosomal ATPase affects ATP hydrolysis but not binding to the spliceosome. Mol. Cell. Biol. 12: 3540-3547.

Seraphin, B. and M. Rosbash. 1989. Identification of functional U1 snRNA-pre-mRNA complexes committed to spliceosome assembly and splicing. Cell 59: 349-358.

Strauss, E.J. and C. Guthrie. 1991. A cold-sensitive mRNA splicing mutant is a member of the RNA helicase gene family. Genes \& Dev. 5: 629-641.

Studier, F.W. and B.A. Moffatt. 1986. Use of bacteriophage T7 RNA polymerase to direct selective high-level expression of cloned genes. J. Mol. Biol. 189: 113-130.

Theunissen, O., F. Rudt, U. Guddat, H. Mentzel, and T. Pieler. 1992. RNA and DNA binding zinc fingers in Xenopus TFIIIA. Cell 71: 679-690.

Vijayraghavan, U., M. Company, and J. Abelson. 1989. Isolation and characterization of pre-mRNA splicing mutants of Saccharomyces cerevisiae. Genes \& Dev. 3: 1206-1216.

Whittaker, E. and J.D. Beggs. 1991. The yeast PRP8 protein interacts directly with pre-mRNA. Nucleic Acids Res. 19: $5483-5489$.

Zamore, P.D., J.G. Patton, and M.R. Green. 1992. Cloning and domain structure of the mammalian splicing factor U2AF. Nature 355: 609-614.

Zhang, M., P.D. Zamore, M. Carmo-fonseca, A. Lamond, and M. Green. 1992. Cloning and intracellular localization of the U2 small nuclear ribonucleoprotein auxiliary factor small subunit. Proc. Natl. Acad. Sci. 89: 8769-8773. 


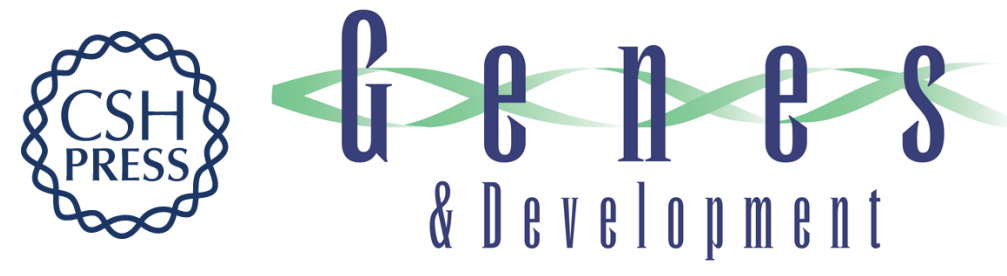

\section{Interactions between PRP9 and SPP91 splicing factors identify a protein complex required in prespliceosome assembly.}

$P$ Legrain, C Chapon and F Galisson

Genes Dev. 1993, 7:

Access the most recent version at doi:10.1101/gad.7.7b.1390

References This article cites 54 articles, 26 of which can be accessed free at:

http://genesdev.cshlp.org/content/7/7b/1390.full.html\#ref-list-1

License

Email Alerting

Receive free email alerts when new articles cite this article - sign up in the box at the

Service top right corner of the article or click here.

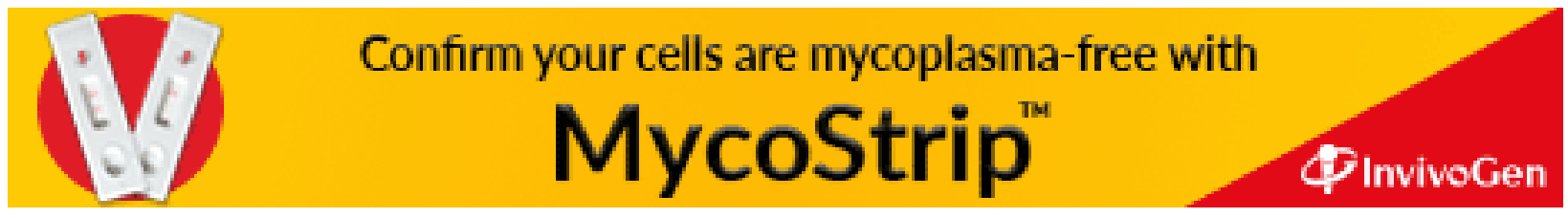

